\title{
Electroencephalographic seizures during cardiopulmonary bypass
}

\author{
J. STOCKARD, P. CALANCHINI, R. BICKFORD, AND T. BILLINGER \\ From the Departments of Neurosciences and Anesthesiology, University of California, San Diego, \\ and the Department of Neurology, Presbyterian Hospital, San Francisco, California, U.S.A.
}

SYNOPSIS Eleven cardiac operations are reported in which there was electroencephalographic and/or clinical evidence of seizure activity during cardiopulmonary bypass (CPB). In four patients seizure activity appeared after acute episodes of cerebral ischaemia resulting from either hypotension or pump-generated emboli occurring at the beginning of CPB, or from air embolism occurring at the end of CPB when the myocardium was closed and defibrillated. In the remaining seven patients the seizures appeared to result from the synergistic action of a toxic substance in the perfusate with pre-existing or CPB-induced alterations in cerebral physiology.

While numerous reports have appeared over the last 15 years documenting the depression of electrocortical activity which frequently accompanies cardiopulmonary bypass (CPB) (Theye et al., 1957; Silverstein et al., 1960; Lorenz and Hehrlein, 1970), excitatory or epileptiform electroencephalographic (EEG) activity associated with $\mathrm{CPB}$ has rarely been observed. The lack of data on epileptic phenomena during CPB may partly reflect the relative infrequency with which the intraoperative EEG is recorded and the use of neuromuscular blocking agents during CPB which would mask any clinical manifestations of seizures. Although probably very rare, seizure activity during CPB is of clinical importance inasmuch as it represents a potentially fatal complication of open-heart surgery. The dangers of having a violent motor seizure during a critical portion of the surgical procedure are obvious. Even if complete neuromuscular blockade is present at the time that electrical seizure activity initially develops, the later unmasking of motor convulsions as the muscle relaxants wear off could pose an unallowable circulatory stress (Storm van Leeuwen et al., 1961). The possibilities of progression to status epilepticus (Seamans et al., 1968; Radvanyi et al., 1970) or of 'consumption anoxia' of the cerebral cortex resulting from the greatly increased oxygen demands of the discharging neurones (Davies and
Rémond, 1947; Meyer and Waltz, 1961) further suggest the desirability of controlling even a purely electrographic seizure during CPB.

The present study investigates the electroencephalographic and clinical circumstances of a number of epileptic seizures occurring during extracorporeal circulation in an attempt to elucidate underlying mechanisms and appropriate therapy of these phenomena and their possible relevance to clinical epilepsy.

\section{METHOD}

Eleven electrographic seizures during CPB are reported which occurred in a combined series of 280 patients undergoing cardiac surgery with CPB at our hospitals between 1965 and 1972. In this series, nonpulsatile extracorporeal perfusion was performed with a roller pump with either a bubble, membrane, or disc oxygenator. The internal jugular vein and radial or femoral artery were cannulated in all patients for continuous measurement of arterial and venous pressures. Arterial blood gas and serum electrolyte analyses were performed routinely. During CPB, normocapnia and arterial oxygen tensions in the range of $200 \mathrm{mmHg}$ were maintained. Extracorporeal flow rates of $2 \cdot 21 . / \mathrm{min} / \mathrm{m}^{2}$ of body surface area were maintained in all cases. Moderate hypothermia of 28 to $34^{\circ} \mathrm{C}$ was induced during long procedures.

Four to 14 bipolar EEG channels were recorded from frontal, central, occipital, and temporal disc 
TABLE

CLINICAL DETAILS

\begin{tabular}{|c|c|c|c|c|c|c|c|}
\hline $\begin{array}{l}\text { Case } \\
\text { no. }\end{array}$ & $\begin{array}{l}\text { Age } \\
(y r)\end{array}$ & Operation & $\begin{array}{l}\text { Type of } \\
\text { oxygena- } \\
\text { tor }\end{array}$ & $\begin{array}{l}\text { Intraoperative } \\
\text { EEG event }\end{array}$ & $\begin{array}{l}\text { Concomitant } \\
\text { operative } \\
\text { event }\end{array}$ & $\begin{array}{c}\text { Preoperative EEG } \\
\text { or neurological } \\
\text { status }\end{array}$ & $\begin{array}{l}\text { Postoperative EEG or } \\
\text { neurological status }\end{array}$ \\
\hline 1 & 53 & OMC & B & \multirow{2}{*}{$\begin{array}{l}\text { Bifrontal spike-and- } \\
\text { wave activity } \\
\text { Right-sided sharp waves } \\
\text { spreading to other } \\
\text { hemisphere }\end{array}$} & \multirow{2}{*}{$\begin{array}{l}\text { Beginning of } \\
\text { CPB; arterial } \\
\text { hypotension, } \\
\text { venous } \\
\text { hypertension }\end{array}$} & \multirow{2}{*}{$\begin{array}{l}\text { Bifrontal delta; } \\
\text { history of TiAs } \\
\text { WNL }\end{array}$} & No change from pre-op. \\
\hline 2 & 39 & CABG & $\mathbf{B}$ & & & & WNL \\
\hline $\begin{array}{l}3 \\
4\end{array}$ & $\begin{array}{l}55 \\
11\end{array}$ & $\begin{array}{l}\text { AVR } \\
\text { Repair, tetralogy of }\end{array}$ & $\begin{array}{l}\mathbf{M} \\
\mathbf{M}\end{array}$ & \multirow{4}{*}{$\begin{array}{l}\text { Bursts of spike activity } \\
\text { alternating with } \\
\text { suppressions }\end{array}$} & \multirow[b]{2}{*}{$\begin{array}{l}\text { Withdrawal of } \\
\text { CPB; de- } \\
\text { fibrillation }\end{array}$} & $\begin{array}{l}\text { WNL } \\
\text { WNL }\end{array}$ & $\begin{array}{l}\text { Bilateral EEG slowing } \\
\text { Bilateral EEG slowing and }\end{array}$ \\
\hline 5 & 6 & $\begin{array}{l}\text { Fallot } \\
\text { Repair, patent } \\
\text { foramen ovale, } \\
\text { and pulmonic } \\
\text { stenosis }\end{array}$ & $\mathbf{M}^{*}$ & & & WNL & $\begin{array}{l}\text { grand mal seizures } \\
\text { Paroxysmal, high-voltage } \\
\text { discharges from r. hemi- } \\
\text { sphere; urticaria }\end{array}$ \\
\hline 6 & 6 & $\begin{array}{l}\text { Repair of VSD and } \\
\text { pulmonic stenosis }\end{array}$ & $\mathbf{M}^{*}$ & & CPB & $\begin{array}{l}\text { History of seizures; } \\
\text { family history of } \\
\text { epilepsy; diffusely } \\
\text { abnormal EEG }\end{array}$ & $\begin{array}{l}\text { Facial twitching and arm } \\
\text { jerks; ankle clonus; } \\
\text { Babinski reflexes }\end{array}$ \\
\hline 7 & 5 & Closure of VSD & $M^{*}$ & & CPB & $\begin{array}{l}\text { Diffusely abnormal } \\
\text { EEG }\end{array}$ & $\begin{array}{l}\text { Facial twitching and clonic } \\
\text { arm jerking }\end{array}$ \\
\hline 8 & 34 & AVR & $\mathbf{M}^{*}$ & \multirow{4}{*}{$\begin{array}{l}\text { Progressive increase in } \\
\text { epileptiform activity } \\
\text { culminating in } \\
\text { generalized } \\
\text { spike-and-wave } \\
\text { activity }\end{array}$} & CPB & $\begin{array}{l}\text { Metabolic } \\
\text { encephalopathy } \\
\text { with only 1-2 Hz, } \\
5 \mu \mathrm{V} \text { EEG activity }\end{array}$ & $\begin{array}{l}\text { Expired intraoperatively; } \\
\text { neuropathology WNL; } \\
\text { urticaria }\end{array}$ \\
\hline 9 & 46 & AVR, MVR & $\mathbf{M}^{*}$ & & CPB & WNL & $\begin{array}{l}\text { Slowly resolving psychosis in } \\
\text { first postoperative week }\end{array}$ \\
\hline 10 & 29 & MVR & $M^{*}$ & & CPB & WNL & $\begin{array}{l}\text { Expired intraoperatively; } \\
\text { neuropathology WNL; } \\
\text { urticaria }\end{array}$ \\
\hline 11 & 18 & $\begin{array}{l}\text { Excision of hyper- } \\
\text { trophic myo- } \\
\text { cardium }\end{array}$ & $M^{*}$ & & CPB & WNL & WNL \\
\hline
\end{tabular}

$\mathbf{A V R}=$ aortic valve replacement $; \mathbf{C A B G}=$ coronary artery bypass graft $; \mathrm{OMC}=$ open mitral commissurotomy; $\mathbf{M V R}=$ mitral valve replacement; $\mathbf{B}=$ bubble; $\mathbf{M}=$ membrane; $\mathbf{M}^{*}=$ oxygenator with the defective membrane; WNL= within normal limits.

electrodes placed according to the International 10 20 System (Jasper, 1958). EEG data were recorded continuously on paper with an 8 or 16 channel electroencephalograph and, in some cases, were also recorded on magnetic tape with a frequency-modulation tape recorder. To relate the evolution of seizure activity to circulatory changes, four-second epochs of taped EEG data were subjected to power spectral analysis and these power spectra were vertically compressed and plotted against arterial and venous pressures, as described in detail elsewhere (Stockard et al., 1972).

\section{RESULTS}

Data for the 11 patients having seizures during CPB are summarized in the Table. The patients' age ranged from 5 to 55 years with a mean of $27 \pm 5.8$ (SEM), which is representative of the larger population from which they were drawn. The distribution of the various types of operations within the seizure group also paralleled that of the series as a whole.

As can be seen in the Table, there was a highly significant association of seizure activity with the use of the membrane oxygenator, a relationship which will be further discussed. Although each of the three types of oxygenator was employed fore approximately one-third of the total number of cases, nine of the seizures occurred while using the membrane oxygenator, two while using the bubble oxygenator, and none while using the disc oxygenator. The average time elapsed between the commencement of CPB and the onset of seizure activity was less than five minutes for the two seizures occurring with the bubble oxygenator (cases 1 and 2) and over two and a half hours for six of the nine seizures (cases 6-11) occurring with the membrane oxygenator; the other three seizures occurring with the membrane oxygenator (cases 4-6) did so at the end of CPB as the aorta was unclamped and the heart defibrillated. These statistics alone suggest that different mechanisms were involved.

The development of electrographic seizure activity at the beginning of CPB with the bubble oxygenator appeared to be related to sudden drops in cerebral perfusion pressure occurring at that time. The precipitous fall in systemic arterial pressure (SAP) in these and several other cases with the bubble oxygenator resulted 


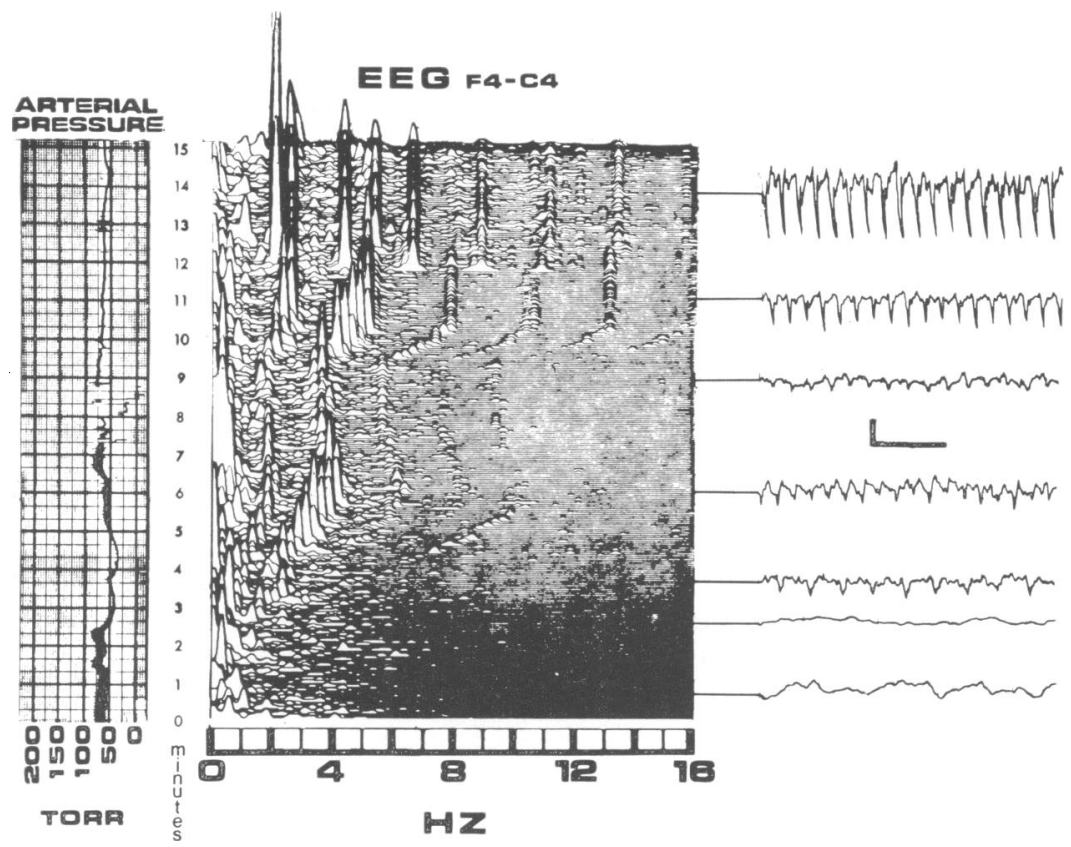

FIG. 1. Development of an electrographic seizure during $C P B$ in case 1, shown both in conventional form (right) and as a compressed spectral array (CSA). Time progresses vertically at the rate indicated at left and EEG frequency is on the X-axis. Peak heights in the CSA are proportional to the EEG power expressed at those frequencies. The establishment of full extracorporeal perfusion is indicated by the loss of pulsatility of the arterial pressure tracing $2.5^{\circ}$ minutes into the tracing. The subsequent fall in arterial pressure to $35 \mathrm{mmHg}$ was accompanied by a rise in jugular venous pressure to $30 \mathrm{mmHg}$. The EEG amplitude decreased to $2-5 \mu \mathrm{V}$ at this time followed by the appearance of $2 \cdot 25$ $\mathrm{Hz}$ sharp waves which gradually increased in frequency and amplitude. The heart was fibrillated 5 minutes after the onset of full perfusion and thus no ECG artefact was seen after that point (minute 8). Calibration $=20 \mu \mathrm{V}, 1$ second. F4-C4 = right fronto-central derivation.

from the haemodilutional effect of going on bypass and the consequent fall in vascular resistance (from the Poiseuille-Hagen relationship). In both cases 1 and 2, a simultaneous rise in jugular venous pressure (JVP) to above $30 \mathrm{mmHg}$ reduced the effective cerebral perfusion pressure to less than $10 \mathrm{mmHg}$. In case 1 , this resulted initially in the reduction of EEG amplitude to less than $5 \mu \mathrm{V}$, as seen at the bottom of Fig. 1 . Within several minutes, repetitive sharp waves developed which increased in frequency and amplitude and evolved into continuous $4 \mathrm{~Hz}$ negative spike activity. Ten milligrams of diazepam were given intravenously 15 minutes later and a reduction in the seizure activity was noted (Fig. 2). The seizure discharges in this patient originated bifrontally and spread posteriorly to involve the central parasagittal channels. This is of particular interest in view of the marked medial bifrontal slowing in the preoperative EEG of this patient (Fig. 3) and the long clinical history of transient ischaemic attacks, most with symptoms of bilateral anterior cerebral artery involvement.

In case 2, a similar drop in SAP and simultaneous rise in JVP occurred at the beginning of bypass and was also associated with electrographic seizure activity. However, the right- 

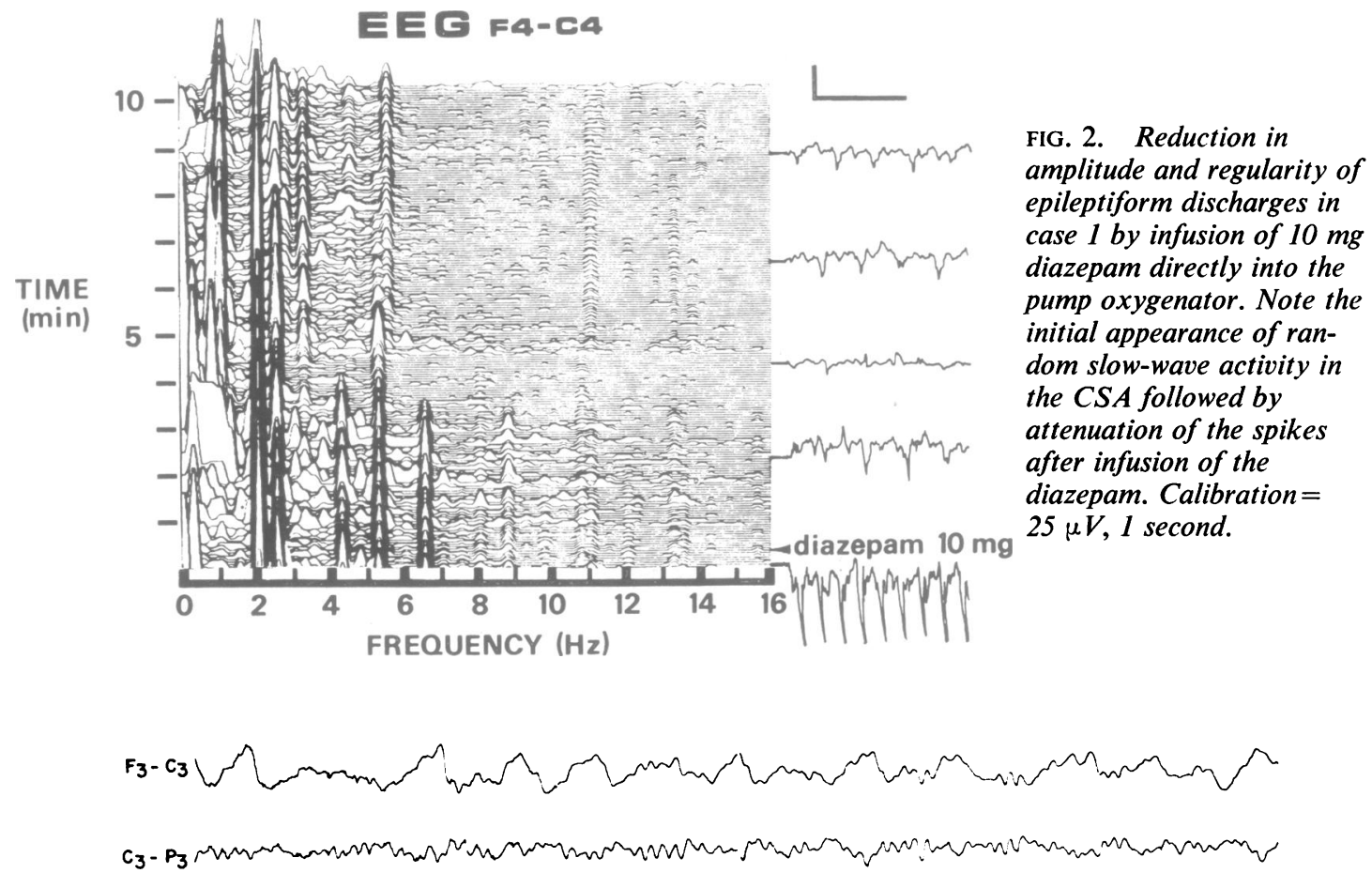

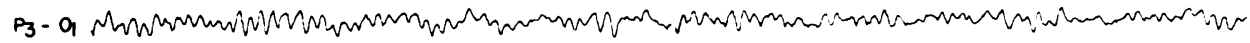

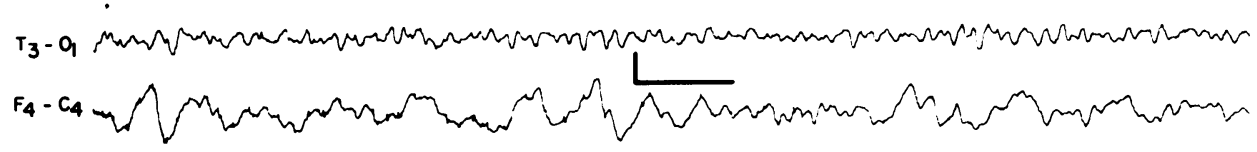

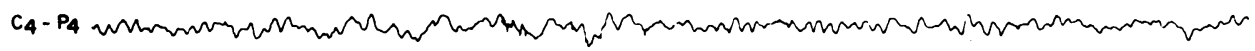

$P_{4}-0_{2}$ Nun

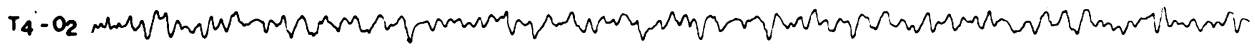

FIG. 3. Conventional EEG recording obtained two days preoperatively in case 1 which shows marked bifrontal delta activity. The eyes were closed and did not move during the 11-second interval shown, as indicated by four periorbital electrodes around each eye. Calibration $=50 \mu \mathrm{V}$, 1 second.

sided origin of this activity suggested that cerebral embolism was responsible. As shown in Fig. 4, unilateral slowing appeared shortly after full extracorporeal flow was attained (a point indicated by the loss of pulsatility in the SAP tracing). After $2 \cdot 5$ minutes, this right-sided delta activity evolved into repetitive sharp waves of increasing frequency which then spread to the left hemisphere (Figs 4 and 5). As in the previous case, diazepam infused directly into the pump reduced the intensity of the spike activity, which later disappeared completely in association with restoration of higher arterial pressure and return of the alpha rhythm (Fig. 6).

In three of the cases (cases 3,4 , and 5 ) in which a membrane oxygenator was being 

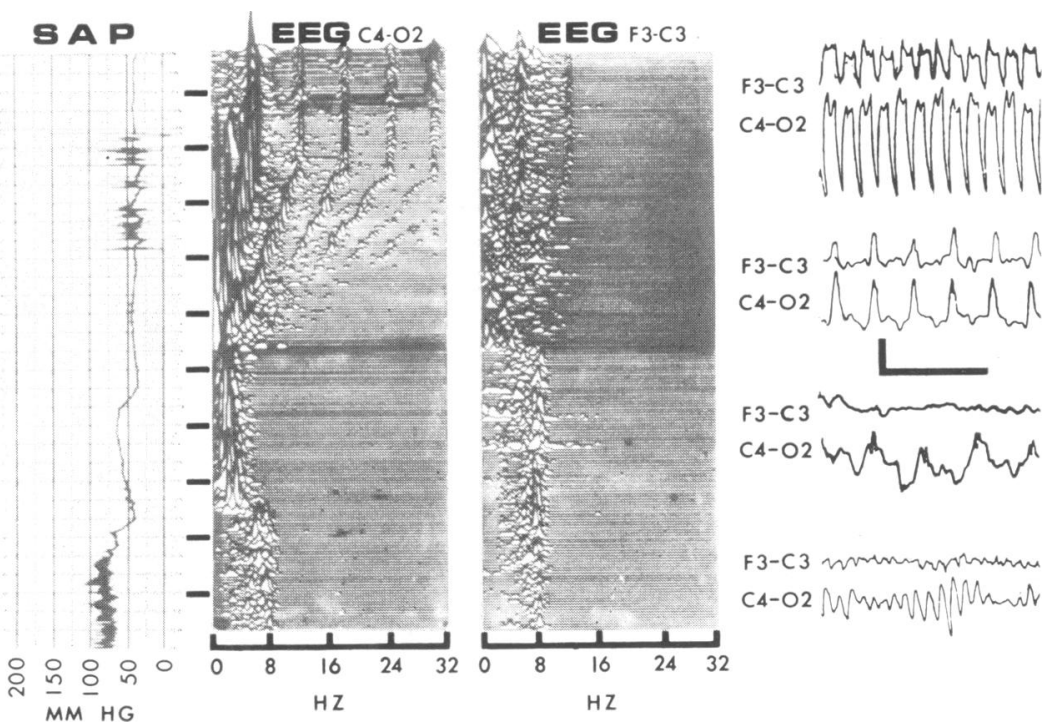

FIG. 4. Development and spread of epileptiform activity in case 2 after probable right-hemispheric embolization at the onset of $C P B$. Minutes are indicated by the marks between the systemic arterial pressure (SAP) tracing and the compressed spectral array for the right centro-occipital EEG channel (C4-O2). High-voltage slow waves suddenly appeared over the right hemisphere about 1 minute after the establishment of full extracorporeal perfusion. Repetitive sharp waves developed 2.5 minutes later which increased in frequency and amplitude and spread to the opposite hemisphere. Calibration $=50 \mu \mathrm{V}, 1$ second. F3-C3 = left fronto-central derivation.
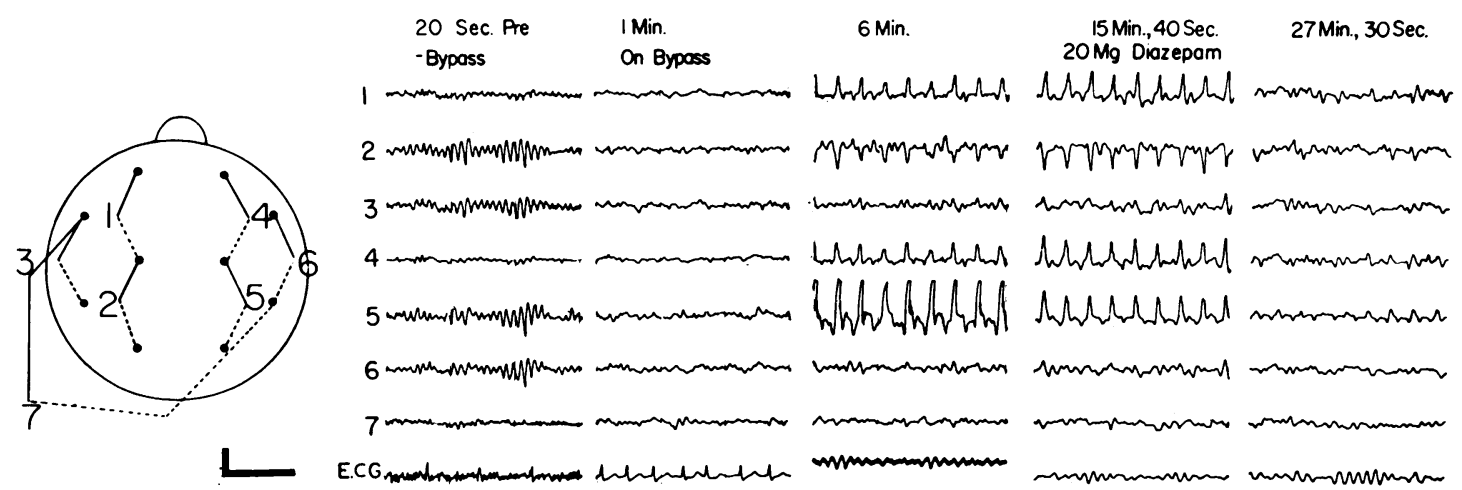

FIG. 5. Conventional EEG recording showing the parasagittal distribution of epileptiform activity in case 2. One minute after achievement of full bypass, the alpha activity suddenly disappeared (column 2) followed seconds later by the appearance of high-voltage delta activity in channels 4-6 (not shown). Also not shown is the increase in frequency of the discharges to $6 \mathrm{~Hz}$ which occurred 7 minutes after the commencement of $C P B$ (Fig. 4) and was later reversed with $20 \mathrm{mg}$ diazepam (column 5). Note the absence of QRS complexes after the first few minutes of bypass and the resemblance of the ECG fibrillation potentials to alpha activity. Calibration= $75 \mu \mathrm{V}, 1$ second. 


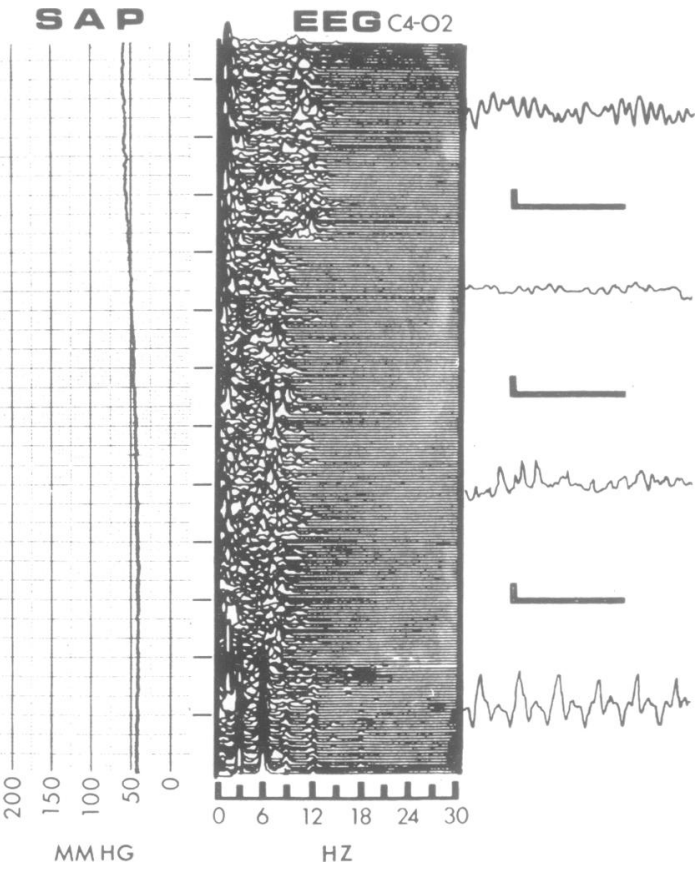

FIG. 6. Termination of the electrographic seizure in case 2 followed by recovery of alpha activity. Four $5 \mathrm{mg}$ doses of diazepam given at 1 minute intervals 13-16 minutes after the commencement of CPB resulted in slowing of the epileptiform discharges from $6 \mathrm{~Hz}$ to $3 \mathrm{~Hz}$ followed four minutes later by a reduction in their amplitude (bottom half of CSA). Note the subsequent return of alpha activity with the rise in $S A P$ above $50 \mathrm{mmHg}$. Calibration $=25 \mu \mathrm{V}, 1$ second. employed, seizure activity may have been precipitated by cerebral air embolism. In each of these cases, there had been difficulty in evacuating residual air from the left ventricle before closure. In cases 3 and 4, the EEG was wellmaintained up to the point where CPB was withdrawn and the heart defibrillated. Immediately after defibrillation in these cases, slowing and loss of amplitude were seen in the EEG; this was followed within 15 minutes by the eruption of spike activity occurring in bursts of approximately one minute duration. Residual slow-wave activity was present bilaterally in the post-ictal EEG in each case and, in case 4, the patient had grand mal seizures postoperatively.

In case $5,200 \mu \mathrm{V}, 2 \mathrm{~Hz}$ spike activity occurred 60 seconds after the unclamping of the aorta and defibrillation (Fig. 7). Twenty seconds after defibrillation, bilateral flattening of the EEG occurred which, after 40 seconds, was interrupted by a 30 second burst of spike activity. A second 30 second burst of spiking followed a brief inter lude of electrical silence. The post-ictal records was dominated by low-voltage $8-9 \mathrm{~Hz}$ activity although paroxysmal $150 \mu \mathrm{V}$ slow discharges Tा were recorded from the right hemisphere, as shown in Fig. 7. Postoperatively, the right-sided EEG abnormality persisted, although there were no permanent neurological deficits. In this case several things suggested that the electrographic seizure activity may have resulted from the

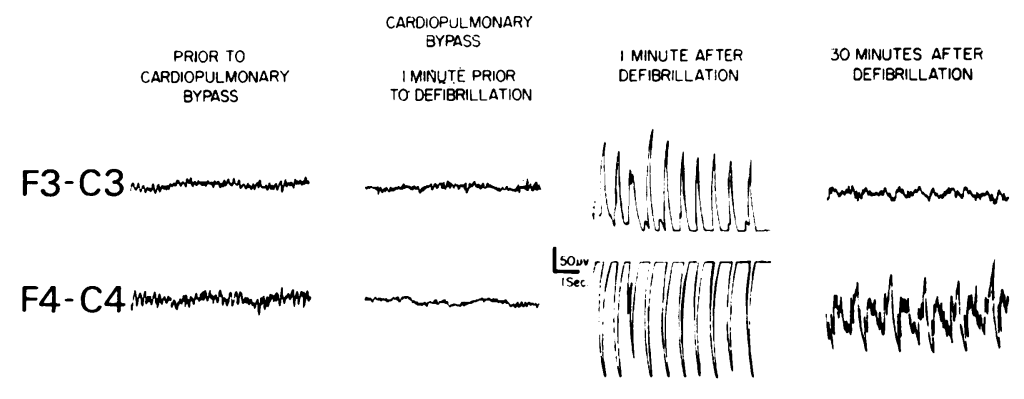

FIG. 7. High-amplitude spike discharges in case 5 after initial flattening of the EEG after defibrillation. The symmetrical $8 \mathrm{~Hz}$ background rhythm which was present before $C P B$ was well maintained throughout the perfusion up to the time of defibrillation. Paroxysmal delta activity was recorded from the right hemisphere during the remainder of the operative procedure and residual asymmetry persisted in the EEG postoperatively. 
synergistic action of anoxia and a toxic substance in the perfusate. This patient, who had not received penicillin or any other common allergen, developed severe generalized urticaria immediately after CPB. Furthermore, this particular patient was perfused at a time when a defective membrane was being employed in the oxygenator. Six other patients (cases 6-11) had electrographic and/or clinical evidence of seizure activity during CPB in the relatively short time (six months) during which this membrane was used.

In these six patients, the seizures occurred in the middle two-thirds of the CPB procedure during haemodynamically stable periods in which the aorta was cross-clamped and no drugs which cross the blood-brain barrier were administered. The membrane being used in these cases was composed of a silicone elastomer, dimethylpolysiloxane (DMPSO). It was later discovered that, during vulcanization, this DMPSO membrane had been subjected to approximately twice the intended temperature for over twice as long as specified. In these conditions, it is likely that pyrolysis products of DMPSO were produced which may later have been released into the perfusate during CPB. The widespread urticaria (similar to that in case 5) which was seen after CPB in the two of these patients with the longest perfusion times supports the hypothesis that some toxic substance had accumulated in these patients during CPB. The progressive increase in epileptiform EEG activity during CPB that was seen in all six patients also suggests that the evolution of seizure activity was dose-related to some aspect of the perfusion.

Electrographic seizure activity was not seen in several other cases in which this same membrane was used during CPB. This selective occurrence of electrographic seizures in six patients may be explained by the increased exposure of these patients to the putative epileptogen as well as by pre-existing alterations in cerebral physiology which might have predisposed to seizures in several of the patients. The average duration of perfusion in the seizure patients was 156 minutes, almost twice as long as the average perfusion for patients without seizures for whom the same oxygenator was used. Furthermore, the onset of seizure activity did not occur until after an average of 146 minutes of perfusion, long after normal circulation had been restored in the average patient not having electrographic seizures.

In addition, the preoperative neurological status or EEG of three of the seizure patients (cases $6,7,8$ ) suggested that a lowered seizure threshold might be present. Two of these were children with congenital cardiac defects of the cyanotic type who had abnormal preoperative EEGs. One (case 6) had a history of seizures and an epileptic sister. The third of these patients (case 8) was suffering from severe azotaemia and was obtunded before operation; the pre-bypass EEG in this case was virtually isoelectric.

There were no permanent neurological deficits in any of the four surviving patients having these presumably toxic seizures during CPB. One patient (case 9) manifested psychiatric disturbances postoperatively which were most severe in the first postoperative week and improved thereafter. This complication is more probably attributable to the extremely long perfusion in this case ( 4.5 hours) in which there was a high degree of haemolysis $(30 \mathrm{mg} / 100 \mathrm{ml}$. rise in free haemoglobin per hour) during CPB. Two of the six patients (cases 8,10 ) died intraoperatively from cardiovascular causes and neuropathological studies revealed no abnormalities at either gross or microscopic levels. In each case, examination of the brains under polarized light was negative.

Clinical manifestations of seizure activity, consisting of facial twitching and clonic contractions of both arms, were seen in two patients (cases 6 and 7) who were incompletely curarized.

\section{DISCUSSION}

From an EEG standpoint, the most interesting feature of the anoxic seizures in this series was the rapidity with which spike activity appeared in the EEG after the ischaemic insult. With regard to convulsions resulting from anoxia, Gastaut et al. (1958) have emphasized the distinction between tonic brain-stem release phenomena (associated with slowing or flattening of the EEG) and true epileptic seizures with spike discharges in the EEG. The convulsive phenomena which sometimes immediately follow episodes of cerebral anoxia are classically included in the 
former category and it is generally considered that authentic epileptic seizures are a later response. Although the bulk of animal research supports this contention, there have been several reports of epileptiform EEG changes as an acute manifestation of cerebral anoxia in patients undergoing open-heart surgery. Arfel et al. (1961) reported a patient with a normal preoperative EEG in whom $6 \mathrm{~Hz}$ rolandic spikes developed concomitantly with a rise in central venous pressure to $30 \mathrm{mmHg}$ during CPB. The rise in venous pressure occurred at a time when the mean arterial pressure was $80 \mathrm{mmHg}$ and thus represents a reduction in effective cerebral perfusion pressure to approximately $50 \mathrm{mmHg}$. This is the cerebral perfusion pressure at which the more conventional EEG changes of cerebral ischaemia-slowing or flattening-have most frequently been observed (Kavan et al., 1959; Van Bergen et al., 1964; Juneja et al., 1972). Radvanyi et al. (1969) reported the development of spike activity 16 minutes after defibrillation in a case of probable cerebral embolism during open-heart surgery. High-amplitude spiking was recorded 20 minutes after a post-defibrillation embolus by Arfel (1967). The post-embolic spike activity in this case followed phases of initial slowing and flattening (15 seconds after defibrillation), recovery of frequency and amplitude (three minutes after) and high-voltage slowing (12 minutes after). In studies of experimental cerebral embolism in dogs, Masland and Netsky (1961) recorded unilateral repetitive sharp waves 37 minutes after the injection of barium sulphate into the ipsilateral internal carotid artery. The electrographic seizures observed in cases 1-4 also suggest that epileptiform EEG changes can occur as an acute response to cerebral anoxia, although, in each of these cases, the brain was also being subjected to the irritating effects of extracorporeal perfusion.

When considering the total number of patients in the series, however, spike discharges or repetitive sharp waves were recorded in only a small fraction $(<5 \%)$ of the patients in whom ischaemic episodes occurred. The usual EEG response in these cases was bilateral slowing or flattening with hypotension (Stockard et al., 1973) and unilateral (usually right-sided) slowing and flattening immediately after defibrillation (Stockard and Schauble, unpublished data).
Spike activity may conceivably have been related to hypotension in case 1 in which it appeared bilaterally in the same channels in which there had been a severe focal EEG abnormality preoperatively which was compatible with prior embolic damage in the distribution of the anterior cerebral arteries. As pointed out by Lorenz and Hehrlein (1970), focal anoxia-such as may have been manifested by spike activity in this casecan result from a lowering of the systemic blood pressure which causes cerebrovascular insufficiency in a previously damaged area. The precipitation of generalized epileptiform EEG changes by hypotension has been reported before by Lawrence (1966) who observed an 'epileptic' patient with a normal interictal EEG who had grand mal seizures accompanied by $1,000 \mu \mathrm{V}$ spikes every time her systolic blood pressure fell below $80 \mathrm{mmHg}$. The patient had no subsequent seizures after long-term elevation of her blood pressure with a therapeutic regimen of mephentermine and phenylephrine. The role of hypotensive ischaemia in case 1 is purely speculative however, and focal irritation of a previously damaged area by the perfusate or by micro emboli is a more likely explanation of the finding in this case.

The origin of the epileptiform activity in case 2 is not clear because, although it appeared in association with a profound reduction in cerebral perfusion pressure, it developed unilaterally before spreading to the opposite hemisphere. In this case in which there was no clinical evidence of seizure activity (the patient was completely curarized) and in which the EEG abnormality was so unusual, it was important to rule out the possibility of pulsation artefact produced by the heart-lung machine as was reported by Wright et al. (1972). This was done by observing the independence of extracorporeal flow rate (and thus pulsation rate) from the frequency of the EEG discharges. The topographical spread of discharges from a focus, the suppression of epileptiform activity with diazepam, and the final disappearance of the activity under the same bypass conditions in which it had arisen, all indicate that the activity was of cerebral origin.

The pattern of the seizures occurring in cases 6-11 suggests that they resulted from cumulative exposure of the central nervous system to a potential epileptogen in the perfusate, one pos- 
sibly extracted from the overcured DMPSO membrane. Dimethylpolysiloxane (DMPSO) fluid is capable of damaging nervous tissue (Mukai, 1971) but its relative toxicity to the central nervous system has been shown to be minimal (Hine et al., 1969); furthermore, DMPSO rubber (of which the membrane was composed) is not neurotoxic when in direct contact with brain or peripheral nervous tissue (Ames, 1967; Ducker and Hayes, 1967, 1968; Weiss and Raskind, 1969). Therefore, it is likely that the epileptogen in these cases was not DMPSO itself but a pyrolysis product of DMPSO which was extracted from the overcured membrane during perfusion. Indeed, it has been demonstrated that the extractable content of DMPSO rubber increases as it is overcured (Carmen and Kahn, 1969), although the byproducts formed by such overcuring have not been characterized.

Cardiopulmonary bypass has been shown to increase the permeability of the blood-brain barrier (Hodges et al., 1958) and it is possible that a breakdown of the blood-brain barrier was critical to the epileptogenicity of the putative DMPSO derivative, just as it is critical to the epileptogenicity of penicillin during CPB (Seamans et al., 1968). In case 5, in which the duration of perfusion was only 45 minutes, seizure activity was not seen until after the probable air embolization of the right hemisphere after defibrillation. It is possible that this anoxic accident increased the permeability of the bloodbrain barrier to the DMPSO derivative, thus precipitating seizure activity. By the same mechanism, air embolism has been shown to precipitate seizures in animals previously infused with the potential epileptogen, penicillin (Dobell et al., 1966).

No seizures of the type reported in cases 6-11 occurred after the defective membrane was replaced with a properly vulcanized membrane. In addition to replacement of the membrane, certain other changes in surgical procedure and perfusion technique were made as a result of the EEG abnormalities reported in this study; these included lowering of the patient's head before defibrillation and use of higher extracorporeal perfusion pressures. Since these changes were made, EEGs have been monitored in over 400 patients undergoing CPB and no epileptiform activity has been observed.

This investigation was supported by a fellowship from the Epilepsy Foundation of America held by one of us (J.S.). Much of the actual EEG recording was done by Dr. Z. Sladky, Carol Shattuck, R.EEG.T., and Drene DelCarlo, R.EEG.T., without whose skilled assistance this study would not have been possible. We are also indebted to Dr. James Schauble and Dr. John Osborne for their valuable clinical assistance and technical advice.

\section{REFERENCES}

Ames, R. H. (1967). Ventriculo-peritoneal shunts in the management of hydrocephalus. Journal of Neurosurgery, 27, 525-529.

Arfel, G., Weiss, J., and DuBouchet, X. (1961). EEG findings during open heart surgery with extra-corporeal circulation. In Cerebral Anoxia and the Electroencephalogram, pp. 231249. Edited by H. Gastaut and J. S. Meyer. Thomas: Springfield.

Arfel, G., Casanova, C., Naquet, R., Passelecq, J., and Dubost, C. (1967). Étude électro-clinique de l'embolie gazeuse cérébrale en chirurgie cardiaque. Electroencephalography and Clinical Neurophysiology, 23, 101-122.

Carmen, R., and Kahn, P. (1969). Test in vitro of silicone rubber heart-valve poppets for lipid absorption. Journal of the Association for the Advancement of Medical Instrumentation, 3, 14-17.

Davies, P. W., and Rémond, A. (1947). Oxygen consumption of the cerebral cortex of the cat during metrazol convulsions. Association for Research in Nervous and Mental Disease. Proceedings, 26, 205-217.

Dobell, A. R. C., Wyant, J. D., Seamans, K. B., and Gloor, P. (1966). Penicillin epilepsy. Studies on the blood-brain barrier during cardiopulmonary bypass. Journal of Thoracic and Cardiovascular Surgery, 52, 469-475.

Ducker, T. B., and Hayes, G. J. (1967). A comparative study of the technique of nerve repair. Surgical Forum, 18, 443445.

Ducker, T. B., and Hayes, G. J. (1968). Experimental improvements in the use of silastic cuff for peripheral nerve repair. Journal of Neurosurgery, 28, 582-587.

Gastaut, H., Naquet, R., and Fischer-Williams, M. (1958). The pathophysiology of grand mal seizures generalized from the start. Journal of Nervous and Mental Diseases, 127, 21-33.

Hine, C. H., Elliott, H. W., Wright, R. R., Cavalli, R. D., and Porter, C. D. (1969). Evaluation of a silicone lubricant injected spinally. Toxicology and Applied Pharmacology, 15, 566-573.

Hodges, P. C., Sellers, R. D., Story, J. L., Stanley, P. H., Torres, F., and Lillihei, C. W. (1958). The effects of total cardiopulmonary by-pass procedures upon cerebral function evaluated by the electroencephalogram and a blood brain barrier test. In Extracorporeal Circulation, pp. 279294. Edited by J. G. Allen. Thomas: Springfield, Ill.

Jasper, H. H. (1958). The ten twenty electrode system of the International Federation. Electroencephalography and Clinical Neurophysiology, 10, 371-375.

Juneja, I., Flynn, R. E., and Berger, R. L. (1972). The arterial, venous pressures and the electroencephalogram during open heart surgery. Acta Neurologica Scandinavica, 48, 163-168. 
Kavan, E. M., Brechner, V. L., Walter, R. D., and Maloney, J. V. (1959). Electroencephalographic patterns during intracardiac surgery using cardiopulmonary bypass. Archives of Surgery, 78, 151-156.

Lawrence, R. M. (1966). Hypotension: its relation to epilepsy. International Journal of Neuropsychiatry, 2, 157-159.

Lorenz, R., and Hehrlein, F. (1970). Electroencephalographic findings in heart surgery. Minnesota Medicine, 53, 1069-1076.

Masland, R. L., and Netsky, M. G. (1961). The electroencephalogram in experimental cerebral embolism. In Cerebral Anoxia and the Electroencephalogram, pp. 60-71. Edited by H. Gastaut and J. S. Meyer. Thomas: Springfield, Ill.

Meyer, J. S., and Waltz, A. G. (1961). Relationship of cerebral anoxia to functional and electroencephalographic abnormality. In Cerebral Anoxia and the Electroencephalogram, pp. 307-328. Edited by H. Gastaut and J. S. Meyer. Thomas: Springfield, Ill.

Mukai, N. (1971). Pathogenesis of nerve tissue damage induced by polydimethylsiloxane. Brain and Nerve (Tokyo), 23, 793-803.

Radvanyi, M. F., Leon, L., and Dreyfus-Brisac, M. C. (1969). E.E.G. en chirurgie cardiaque. Surveillance de 80 opérés. Revue Neurologique, 121, 244-246.

Radvanyi, M. F., Leon, L., and Dreyfus-Brisac, C. (1970). EEG in cardiac surgery: survey of 80 cases. (Abstract.) Electroencephalography and Clinical Neurophysiology, 28, 644-645.

Seamans, K. B., Gloor, P., Dobell, A. R. C., and Wyant, J. D. (1968). Penicillin-induced seizures during cardio- pulmonary bypass. A clinical and electroencephalographic study. New England Journal of Medicine, 278, 861-868.

Silverstein, A., Jacobson, E., Kreel, I., and Krieger, H. P. (1960). Effects on the brain of extracorporeal circulation in open heart surgery. Neurology, 10, 987-992.

Stockard, J. J., Schauble, J. F., Billinger, T. W., and Bickford, R. G. (1972). Intraoperative EEG updated: new techniques and future applications. Proceedings of the San Diego Biomedical Symposium, 11, 277-286.

Stockard, J. J., Bickford, R. G., and Schauble, J. F. (1973). Pressure-dependent cerebral ischemia during cardiopulmonary bypass. Neurology, 23, 521-529.

Storm van Leeuwen, W., Mechelse, K., Kok, L., and Z.ierfuss, E. (1961). EEG during heart operations with artificial circulation. In Cerebral Anoxia and the Electroencephalogram, pp. 268-278. Edited by H. Gastaut and J. S. Meyer. Thomas: Springfield.

Theye, R. A., Patrick, R. T., and Kirklin, J. W. (1957). The electro-encephalogram in patients undergoing open intracardiac operations with the aid of extracorporeal circulation. Journal of Thoracic Surgery, 34, 709-717.

Van Bergen, F. H., Buckley, J. J., French, L. A., Dobkin, A. B., and Brown, I. A. (1954). Physiologic alterations associated with hexamethonium-induced hypotension. Anesthesiology, 15, 507-536.

Weiss, S. R., and Raskind, R. (1969). Twenty-two cases of hydrocephalus treated with a silastic ventriculoperitoneal shunt. International Surgery, 51, 13-19.

Wright, J. S., Lethlean, A. K., Hicks, R. G., Torda, T. A., and Stacey, R. (1972). Electroencephalographic studies during open-heart surgery. Journal of Thoracic and Cardio vascular Surgery, 63, 631-638. 